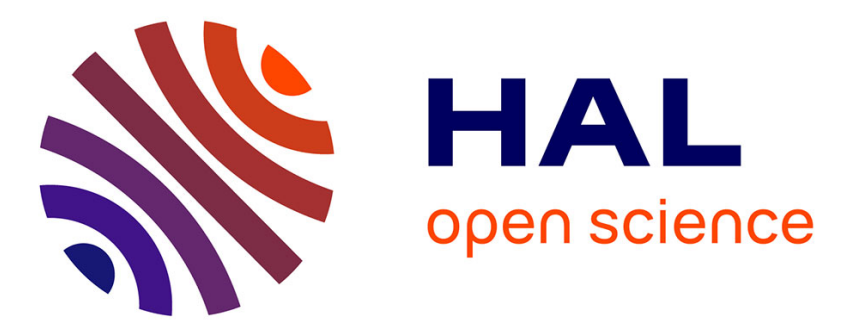

\title{
School performance as a predictor of adulthood obesity: a 21-year follow-up study
}

Saija Alatupa, Laura Pulkki-Råback, Mirka Hintsanen, Niklas Ravaja, Olli T. Raitakari, Risto Telama, Jorma S. A. Viikari, Liisa Keltikangas-Järvinen

\section{- To cite this version:}

Saija Alatupa, Laura Pulkki-Råback, Mirka Hintsanen, Niklas Ravaja, Olli T. Raitakari, et al.. School performance as a predictor of adulthood obesity: a 21-year follow-up study. European Journal of Epidemiology, 2010, 25 (4), pp.267-274. 10.1007/s10654-010-9428-6 . hal-00562717

\section{HAL Id: hal-00562717 https://hal.science/hal-00562717}

Submitted on 4 Feb 2011

HAL is a multi-disciplinary open access archive for the deposit and dissemination of scientific research documents, whether they are published or not. The documents may come from teaching and research institutions in France or abroad, or from public or private research centers.
L'archive ouverte pluridisciplinaire HAL, est destinée au dépôt et à la diffusion de documents scientifiques de niveau recherche, publiés ou non, émanant des établissements d'enseignement et de recherche français ou étrangers, des laboratoires publics ou privés. 


\title{
School performance as a predictor of adulthood obesity: a 21-year follow-up study
}

\author{
Saija Alatupa $\cdot$ Laura Pulkki-Råback • Mirka Hintsanen • \\ Niklas Ravaja · Olli T. Raitakari • Risto Telama • \\ Jorma S. A. Viikari • Liisa Keltikangas-Järvinen
}

Received: 4 February 2009/Accepted: 20 January 2010/Published online: 4 February 2010

(C) Springer Science+Business Media B.V. 2010

\begin{abstract}
We examined the impact of school performance measured in terms of grade point averages (GPAs) in early and middle adolescence (ages 9, 12, and 15), and the impact of school performance throughout the different school stages on adult obesity. The participants were 732 healthy women and men derived from a population-based Cardiovascular Risk in Young Finns Study. GPAs were measured at the ages of 9,12 , and 15 . The body mass index
\end{abstract}

S. Alatupa $\cdot$ L. Pulkki-Råback $\cdot$ M. Hintsanen ·

L. Keltikangas-Järvinen $(\square)$

Department of Psychology, University of Helsinki, P.O. Box 9

(Siltavuorenpenger 1A), 00014 Helsinki, Finland

e-mail: Liisa.Keltikangas-Jarvinen@ @elsinki.fi

L. Pulkki-Råback

Finnish Institute of Occupational Health, Topeliuksenkatu 41A, 00250 Helsinki, Finland

N. Ravaja

Centre for Knowledge and Innovation Research (CKIR),

Helsinki School of Economics (HSE), P.O. Box 21255

(Fredrikinkatu 48), 00076 Aalto, Finland

O. T. Raitakari

Department of Clinical Physiology, Turku University Hospital, P.O. Box 52 (Kiinamyllynkatu 4-8), 20521 Turku, Finland

O. T. Raitakari

Research Centre of Applied and Preventive Cardiovascular Medicine, University of Turku, P.O. Box 52 (Kiinamyllynkatu 10), 20520 Turku, Finland

R. Telama

LIKES Research Centre, Keltavuokko 4 C, 40520 Jyväskylä, Finland

J. S. A. Viikari

Department of Medicine, University of Turku, P.O. Box 52

(Kiinamyllynkatu 13), 20520 Turku, Finland
(BMI; $\mathrm{kg} / \mathrm{m}^{2}$ ), and the waist circumference (WC) were conducted participants being aged 27 or 30 . Birth weight, childhood BMI, adulthood physical activity, maternal and paternal BMI, and maternal education were controlled for. The results showed that low GPAs in each measurement and low GPAs throughout the comprehensive school were a risk factor of adulthood obesity, but only among women. The association remained when controlling for potential confounding variables ( $p$-values in the fully adjusted models $0.026,0.007$, and 0.004 at the ages of 9, 12, and 15, respectively). The results were similar when the BMI was used as a dichotomous variable (BMI $\geq 30$ and BMI <30). Low school performance has previously been associated with higher rates of smoking and alcohol consumption later in life. Our result underscores that low school performance is a health risk factor that should be taken seriously in preventive health education.

Keywords Adulthood obesity - Body mass index . School performance $\cdot$ Longitudinal .

Socioeconomic status - Waist circumference

\section{Introduction}

Obesity and overweight are epidemic global health threats in different generations [1]. Since early last century, the amount of obese adults has increased dramatically both in developed and developing countries [2]. In European 
countries, the prevalence of obesity among adults varies between 7 and 45\% [3]. In Finland, where the present study was conducted, $43 \%$ of women and $57 \%$ of adult men are overweight (body-mass index $\geq 25$ ) [4]. Obesity is an important risk factor for several chronic diseases, including type 2 diabetes [5], heart disease [6], hypertension [7], certain types of cancers [8], psychological malfunctioning [9], as well as accelerated aging and premature death [10]. Consequently, obesity and associated comorbidities have become a high-priced burden in several countries [11].

Even though several early-life risk factors have been identified as etiological causes for later obesity [12], not much is known about the role of timing or duration of different early-life factors to later obesity. One of the most robust predictors of adulthood obesity is exposure socioeconomic disadvantage in childhood [12]. A disadvantaged socioeconomic environment provided by the parents is reflected by students' poor school performance among others [13], which in turn is related with obesity [14]. Child's performance at school may thus provide a link between early-life factors and later obesity.

Previous literature suggest that poor school performance is related with obesity. Although the previous research between school performance and obesity covers school children from different ages, not much is known about the directionality of the association. In their recent review, Taras and Potts-Datema identified a direct relation between poor school performance and obesity across diverse samples of children and adolescents derived from Brazil, China, Finland, Portugal, Thailand, United Kingdom, and USA [14]. The association between poor school performance (measured in terms of GPA) and obesity was found both in cross-sectional and longitudinal data, especially among girls. With one exception [15], the follow-up surveys were conducted in population-based samples the duration of follow-up periods ranging from 1 to 17 years [16-19]. Most of the longitudinal studies examined obesity as a predictor of later school performance [15-18], whereas school performance as a predictor of later obesity was examined in one previous survey [19]. To our knowledge, only a few studies have assessed school performance more than once [16-18], and in these studies, the follow-ups were rather short (1-4 years). Previously, it has been highlighted, that there are no studies examining school performance over multiple time points in relation to obesity [16]. In the present study, we were able to examine whether school performance assessed over several school stages predicts adulthood obesity in a representative national, population based sample.

The associations between obesity and school performance have been essentially similar regardless of how school performance was measured. Negative associations between obesity and school performance were found when
GPAs $[15,16,20-24]$, standardized ability tests $[17,18$, $25,26]$, intelligence quotient [27], years of education [28, 29], educational experiences [30], school functioning [31, $32]$, and school attendance [18, 33] were used as an indicator. In regard to the potential mechanisms underlying the associations of school performance with obesity, it has been suggested that low performance leads into higher levels of emotional stress [34]. Emotional stress, in turn, may predict unfavourable eating behaviours as a coping strategy. Another suggested link is that lower progress at school may be related to an inability to control ones eating behaviour [34].

In the present study, we examined the association of school performance, measured in terms of grade point averages (GPAs), on adulthood body-mass index (BMI) and waist circumference (WC). We used a prospective design of a population-based sample of Finnish school aged children and followed them up until they were 27-30 years of age. We examined whether school performance at three school phases (at 9, 12, and 15 years of age), and changes in school performance across the school phases, predicted later obesity. We took into account the possible confounding effects of a host of early-life factors, such as birth weight, childhood BMI, adulthood physical activity, mother's and father's BMI, and maternal education, which are known to be significant predictors of both school performance and adulthood obesity $[12,18]$. We hypothesized that low grade point averages (GPAs) are associated with higher adulthood BMI and WC. In line with previous evidence [14], we expected the association between school performance and adulthood obesity to be stronger among women.

\section{Methods}

Participants and study design

Participants were from the Cardiovascular Risk in Young Finns study (hereafter abbreviated as The Young Finns study) which is a prospective, ongoing population based study focusing on the development of risk factors of coronary heart disease over 21 years [35]. At the baseline in 1980, a stratified random sample of 3,596 children and adolescents from age cohorts of 3, 6, 9, 12, 15, and 18 years was selected. In order to select participants that were broadly representative of Finnish children and adolescents in terms of living conditions and socioeconomic and demographic background, Finland was divided into five areas according to the location of the university cities with a medical school (Helsinki, Kuopio, Oulu, Tampere and Turku). In each area urban and rural girls and boys were randomly selected on the basis of their personal social 
security number from the Social Insurance Institution's population register, which covers the whole population of Finland. The study plan was approved by local ethics committees of all participating universities, and the study protocol of each study phase corresponded to the proposal by the World Health Organization. All subjects gave written informed consent and the study was conducted in accordance with the Helsinki declaration.

The present study focused on the children from two age cohorts who were 6 (cohort 1) and 9 (cohort 2) years of age at the baseline in 1980 . Grade point averages were measured at three-year intervals: at the ages 9, 12, and 15 years, as shown in Table 1 . The outcome measures were body-mass index (BMI) and waist circumference (WC) which were measured at the 21-year follow-up examination when the participants were 27 and 30 years of age.

All original participants of the Young Finns study belonging to the two age cohorts $(N=1229)$ were invited to take part in the laboratory examination. From this group, 732 participants (390 women, 342 men) had complete BMI and WC data. This group formed the eligible population of the present study. In each separate analysis, the maximum available sample was used, so that, depending on the variables used 546 (296 women and 250 men, GPAs in 3rd grade), 529 (285 women and 244 men, GPAs in 6th grade), 500 (277 women and 223 men, GPAs in 9th grade), or 458 (255 women and 203 men, GPAs throughout the measurements) participants had complete data. Participants who were pregnant $(N=26)$, or who had diagnosis of type I diabetes $(N=11)$ were excluded from the study.

\section{School performance}

The Finnish educational system consists of nine years of compulsory schooling which comprises a six year Elementary School between ages 7 and 12 and a three-year Junior High School between ages 13 and 15. At the end of each school year, students receive annual school reports which include grade point averages (GPAs). The GPAs are the means of marks in several subjects including all of the theoretical subjects, physical education, handwork and arts. School marks range from 4 to 10 (4 is fail, 5-6 poor, 7-8 good and 9-10 excellent). In the present study, GPAs were based on mother-reports at age 9 and self-report at ages 12 , and 15 years.

Body mass and waist circumference

Adulthood BMI and WC were obtained at the follow-up examination in 2001 when the participants were 27 and 30 years old. Body-mass index was calculated as weight in kilograms divided by height in square meters $\left(\mathrm{kg} / \mathrm{m}^{2}\right)$. Weight was measured with a Seca weight scale, and height with a Seca anthropometer. Waist circumference was measured at the level of the twelfth rib (level with the navel in thin subjects) to an accuracy of one millimeter. The measurement of waist circumference was conducted twice and the mean of the two measurements was used. The adulthood measurements of height, weight, and waist circumference were conducted by a nurse during a laboratory examination. Both BMI and WC are recommended parameters for assessing the risk associated with excess obesity [36].

\section{Control variables}

Birth weight, childhood BMI, physical activity in adulthood, mothers and fathers BMI, and maternal education were controlled for because they are known to be significant predictors of both school performance and adulthood obesity [12, 18]. At study baseline, the mother's of the participants were contacted through postal questionnaires. They were requested to report child's birth weight (in grams) and their own completed years of education. Childhood BMI-related measurements of height and weight were conducted at the ages of 9 and 12 by a nurse during a labor examination. Weight was measured with a Seca weight scale and height with a Seca anthropometer. Physical activity was self-reported in 2001 and it was the mean value of five variables including information of the intensity, duration and the frequency of physical activity [37].

Statistical methods

We tested for gender differences in the associations between GPAs and BMI and WC. Because the general

Table 1 Participants' age (years) at the measurements of grade point averages and obesity indexes

\begin{tabular}{llllll}
\hline & \multicolumn{2}{l}{ Grade point average measurements } & & \multicolumn{2}{l}{ Obesity measurements } \\
\cline { 2 - 6 } & Baseline & $\begin{array}{l}\text { At 3-year } \\
\text { follow-up }\end{array}$ & $\begin{array}{l}\text { At 6-year } \\
\text { follow-up }\end{array}$ & $\begin{array}{l}\text { At 9-year } \\
\text { follow-up }\end{array}$ & $\begin{array}{l}\text { At 21-year } \\
\text { follow-up }\end{array}$ \\
\hline Cohort 1 & 6 & 9 & 12 & 15 & 27 \\
Cohort 2 & 9 & 12 & 15 & & 30 \\
\hline
\end{tabular}

Note Grade point average was measured at ages 9, 12, and 15. BMI and WC were measured at the 21-year follow-up when participants had reached 27 and 30 years of age 
linear models showed significant gender interactions ( $p$ values of gender $\times$ grade point average as a predictor of BMI or WC ranged between 0.010 and 0.024 at ages 12 and 15; the interactions ranged between 0.490 and 0.535 at the age 9, however), all of the subsequent analyses were conducted and reported separately by gender.

To examine the association of GPAs at the ages 9, 12, and 15 with BMI and WC in adulthood, linear regressions were computed with BMI and WC as continuous dependent variables each in turn. Two separate regression models were conducted, i.e. a non-adjusted and a fully adjusted model including the variables of birth weight, BMI at the ages of 9 and 12, physical activity in adulthood, mothers and fathers BMI, and years of maternal education.

Additionally, logistic regression analysis was used to examine whether the GPA formed a risk factor for obesity. Obesity was used as the binary outcome variable so that the "obese" group consisted of individuals with BMI $\geq 30 \mathrm{~kg} /$ $\mathrm{m}^{2}$ and the "non-obese" group consisted of individuals with BMI less than $30 \mathrm{~kg} / \mathrm{m}^{2}$ (National Institute for Health and Clinical Excellence, 2006). Odds ratios (OR) and their 95\% confidence intervals (CI) were calculated for an unadjusted and a fully adjusted model (adjusted for age, birth weight, childhood BMI, physical activity in adulthood, maternal and paternal BMI, and maternal education).

Finally, we used the GLM repeated measures procedure to test whether the GPA over the three measurements (or changes in GPA) is associated with adulthood BMI and WC. A non-adjusted and a fully adjusted model (adjusted for age, birth weight, childhood BMI, physical activity in adulthood, maternal and paternal BMI, and maternal education) with the GPA measurements as dependent variable were conducted. All analyses were performed using SPSS software (version 15.0).

\section{Results}

The differences between included and excluded participants at the 2001 follow-up, analyzed with $t$-test and $\chi^{2}$ test, were relatively small. From the current sample a slightly greater proportion of men was excluded than of women $\left(43.3\right.$ vs. $\left.37.7 \%, \chi^{2}[1]=3.976, p=0.046\right)$. The excluded participants had lower GPAs throughout the measurements (means 7.80 vs. $7.70, t=2.775, d f=1104$, $p=0.006$ aged $9,7.94$ vs. $7.73, t=4.424, d f=1035$, $p<0.001$ aged 12 , and 8.06 vs. $7.75, t=5.021, d f=955$, $p<0.001$ aged 15), higher BMI at age of 9 (means 16.47 vs. $16.85, t=-2.064, d f=1159, p=0.039)$, and were physically less active (means 1.94 vs. $1.85, t=2.080$, $d f=874, p=0.038$ ).

Table 2 presents the means and standard deviations of the study variables. Women had significantly higher grade
Table 2 Characteristics of the study variables

\begin{tabular}{|c|c|c|c|c|c|}
\hline & \multirow{2}{*}{\multicolumn{2}{|c|}{$\frac{\text { Women }}{\mathrm{M} \pm \mathrm{SD}}$}} & \multirow{2}{*}{\multicolumn{2}{|c|}{$\frac{\mathrm{Men}}{\mathrm{M} \pm \mathrm{SD}}$}} & \multirow[t]{2}{*}{$P$ value } \\
\hline & & & & & \\
\hline \multicolumn{6}{|l|}{ Grade point averages $(\mathrm{GPA})^{\mathrm{a}}$} \\
\hline GPA at the age of 9 & 7.94 & 0.56 & 7.65 & 0.58 & $<0.001$ \\
\hline GPA at the age of 12 & 8.12 & 0.69 & 7.74 & 0.71 & $<0.001$ \\
\hline GPA at the age of 15 & 8.27 & 0.85 & 7.81 & 0.90 & $<0.001$ \\
\hline \multicolumn{6}{|l|}{ Adulthood outcome variables } \\
\hline BMI & 24.25 & 4.60 & 25.46 & 4.20 & $<0.001$ \\
\hline Waist circumference $(\mathrm{cm})$ & 78.49 & 11.60 & 88.44 & 10.58 & $<0.001$ \\
\hline \multicolumn{6}{|l|}{ Covariates } \\
\hline Birth weight $(\mathrm{kg})$ & 3.43 & 0.52 & 3.53 & 0.61 & 0.036 \\
\hline BMI at the age of 9 & 16.55 & 2.22 & 16.59 & 2.05 & 0.777 \\
\hline BMI at the age of 12 & 18.43 & 2.82 & 18.16 & 2.72 & 0.225 \\
\hline PAI (range from 1-5) & 1.93 & 0.44 & 1.94 & 0.51 & 0.662 \\
\hline Mother's BMI & 23.61 & 3.73 & 23.69 & 3.90 & 0.798 \\
\hline Father's BMI & 25.67 & 3.19 & 25.24 & 2.91 & 0.081 \\
\hline Maternal education (years) & 10.53 & 3.16 & 10.81 & 3.38 & 0.247 \\
\hline
\end{tabular}

Note $P$ value is for the statistical difference between women and men

${ }^{a}$ Possible values are 4-10

point averages (GPAs) than men throughout the measurements. The grade point averages increased somewhat with ascending school grade for both women and men. Mean levels of BMI and WC in adulthood were significantly higher for men than women. Men had an average adulthood BMI of borderline overweight, while in women BMI fell within the normal range (based on the criteria of National Institutes of Health and Clinical Excellence, 2006, that defines normal weight as BMI $<25$ ). With an exception of slightly higher birth weight among men, no significant gender differences were found for other covariates.

Table 3 shows the results of the regression analyses of GPAs predicting adulthood BMI and WC. Among women, lower GPA at each measurement phase was associated with higher adulthood BMI $\left(\beta=-0.137, p=0.018, s r^{2}=\right.$ 0.019 for age $9, \beta=-0.204, p<0.001, s r^{2}=0.042$ for age 12 , and $\beta=-0.231, p<0.001, s r^{2}=0.053$ for age $15)$. In the fully adjusted models, the associations remained significant at each measurement of GPA. No significant associations between GPA and adulthood BMI were found among men.

The results were essentially similar when WC was used as the outcome variable. Lower GPAs at the age of 9 years were associated with higher adult WC in women $(\beta=$ $\left.-0.126, p=0.035, s r^{2}=0.016\right)$. The association between GPAs at the age of 9 years with adulthood WC decreased to borderline significance in the fully adjusted model. GPAs measured at ages 12 and 15 had significant effects on 
Table 3 Standardized beta coefficients of grade point averages (GPAs) at the ages of 9, 12, and 15 in predicting adulthood body mass index (BMI) and waist circumference (WC) in adulthood for women and men separately

\begin{tabular}{|c|c|c|c|c|c|c|c|c|c|c|c|c|}
\hline & \multicolumn{6}{|l|}{ BMI } & \multicolumn{6}{|l|}{ WC } \\
\hline & \multicolumn{3}{|l|}{ Women } & \multicolumn{3}{|l|}{ Men } & \multicolumn{3}{|l|}{ Women } & \multicolumn{3}{|l|}{ Men } \\
\hline & Beta & $p$ & $s r^{2} \#$ & Beta & $p$ & $s r^{2} \#$ & Beta & $p$ & $s r^{2} \#$ & Beta & $p$ & $s r^{2} \#$ \\
\hline \multicolumn{13}{|c|}{ GPA at the age of 9} \\
\hline Unadjusted & -0.137 & 0.018 & 0.019 & -0.043 & 0.502 & 0.002 & -0.130 & 0.026 & 0.017 & -0.045 & 0.478 & 0.002 \\
\hline Fully adjusted $^{\mathrm{a}}$ & -0.103 & 0.026 & 0.010 & -0.016 & 0.759 & 0.000 & -0.086 & 0.075 & 0.007 & 0.001 & 0.983 & 0.000 \\
\hline \multicolumn{13}{|c|}{ GPA at the age of 12} \\
\hline Unadjusted & -0.204 & $<0.001$ & 0.042 & -0.077 & 0.232 & 0.006 & -0.225 & $<0.001$ & 0.051 & -0.077 & 0.230 & 0.006 \\
\hline Fully adjusted $^{\mathrm{a}}$ & -0.134 & 0.007 & 0.016 & -0.041 & 0.453 & 0.001 & -0.148 & 0.004 & 0.019 & -0.023 & 0.703 & 0.000 \\
\hline \multicolumn{13}{|c|}{ GPA at the age of 15} \\
\hline Unadjusted & -0.231 & $<0.001$ & 0.053 & -0.105 & 0.116 & 0.011 & -0.242 & $<0.001$ & 0.059 & -0.089 & 0.184 & 0.008 \\
\hline Fully adjusted $^{\mathrm{a}}$ & -0.147 & 0.004 & 0.019 & -0.028 & 0.632 & 0.001 & -0.154 & 0.003 & 0.020 & 0.003 & 0.962 & 0.000 \\
\hline
\end{tabular}

Note Analyses of the GPAs at the ages of 9, 12, and 15 in predicting adulthood BMI and WC are conducted separately $\# s r^{2}$ is for the squared semi-partial correlation coefficient

a Adjusted for age, birth weight, childhood BMI, physical activity, mother's and father's BMI, and maternal education

adulthood WC in the unadjusted regression models (betas ranged between -0.130 and $-0.242, p$ s between $<0.001$ and $0.026, s r^{2}$ between 0.017 and 0.059 ). The associations between GPAs at the ages of 12 , and 15 on adulthood WC remained significant after adjustment for the confounding variables among women. There was no relation between the grade point averages and waist circumference at any age among men.

In addition, regression analyses were conducted to test whether the associations between GPAs (at the ages of 9, 12, and 15) and adulthood BMI and WC differ among included and excluded women and men. The results showed that the associations between GPAs and BMI were significant in the 6th $(\beta=-0.110, \quad p=0.042$, $\left.s r^{2}=0.012\right)$ and 9th grade $(\beta=-0.129, p=0.022$, $\left.s r^{2}=0.017\right)$ also among men. However, this was the case only for BMI, not for WC. In this connection, it was not possible to conduct a fully adjusted model, since all participants with non-missing data were already taken into the present study.

The results of the logistic regression analyses showed significant associations between GPAs and obesity (obese $\mathrm{BMI} \geq 30$, non-obese $\mathrm{BMI}<30$ ) only among women. The risk of obesity in adulthood was 1.8 or 1.7 times higher for each one standard deviation (SD) decrease in GPAs at age $12(95 \% \mathrm{CI}=1.07-3.04)$ and at age $15(95 \%$ $\mathrm{CI}=1.09-2.62$ ). In other words, moving one SD down in GPA increased the risk for obesity by 70 or $80 \%$. In the fully adjusted models, however, the associations diminished into non-significance at age $12(\mathrm{OR}=1.43,95 \%$ $\mathrm{CI}=0.74-2.75)$ and age $15(\mathrm{OR}=1.28,95 \% \mathrm{CI}=$ $0.77-2.13)$. The logistic regression analyses showed no significant associations between obesity and GPA among men ( $p$ values varying from 0.60 to 0.90 ).

The results of the GLM repeated measures procedure showed a linear trend over the three GPA measurements. Lower GPAs over the three measurements were associated with higher BMIs, and accordingly higher GPAs were associated with lower adulthood BMIs $(F(1,253)=5.594$, $p=0.016, \eta^{2}=0.001$ for women, $F(1,201)=1.022$, $p=0.313, \eta^{2}=0.000$ ).

The association between WC and GPAs was similar to that of BMI and GPAs: low GPAs over the three measurements were associated with high WC and high GPAs were associated with low adulthood WC in both women and men $\left(F(1,253)=8.950, p=0.003, \eta^{2}=0.001\right.$ for women, $F(1,201)=0.678, \quad p=0.411, \eta^{2}=0.000$ for men), but the association was significant only among women. All of the associations for BMI and WC became non-significant when adjusted for the covariates (BMI: $F(1,247)=1.261, \quad p=0.263, \eta^{2}=0.000$ for women, $F(1,195)=0.002, p=0.961, \eta^{2}=0.000$ for men; WC: $F(1,247)=2.941, \quad p=0.088, \eta^{2}=0.000$ for women, $F(1,195)=0.065, p=0.798, \eta^{2}=0.000$ for men).

For illustrative purposes, we plotted the GPA means over the three measurements by adulthood obesity as a binaryoutcome variable (obese: $\mathrm{BMI} \geq 30$; non-obese BMI $<30$ ) separately for women (Fig. 1) and men (Fig. 2). The figures show that non-obese $(\mathrm{BMI}<30)$ women and men had higher GPAs throughout the measurements when controlling for confounding variables. The GPA differences between the groups of non-obese and obese were significant for women in 3rd grade ( $p$-value 0.031 ), but non-significant in 6th and 9th grade $(p=0.126$ in 6 th, and $p=0.055$ in 9 th 
Women

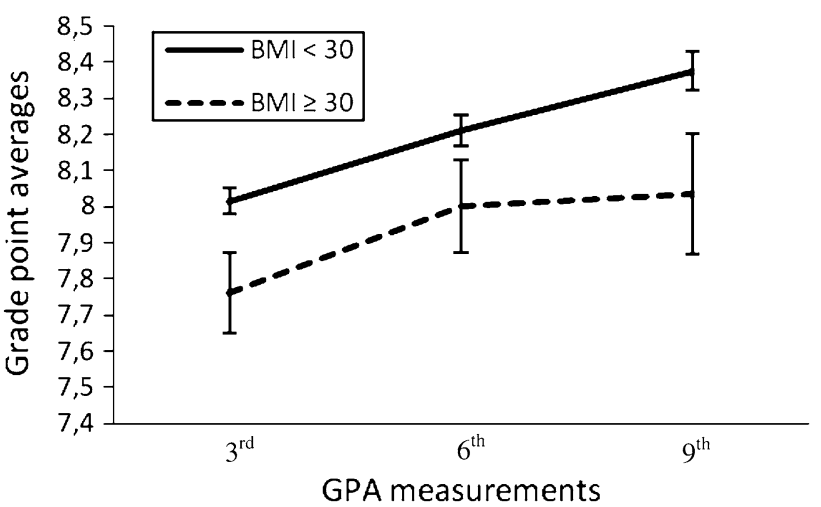

Fig. 1 Fully adjusted GPAs over the three measurements (3rd, 6th, and 9th grade) among non-obese $(\mathrm{BMI}<30)$ and obese $(\mathrm{BMI} \geq 30)$ women

\section{Men}

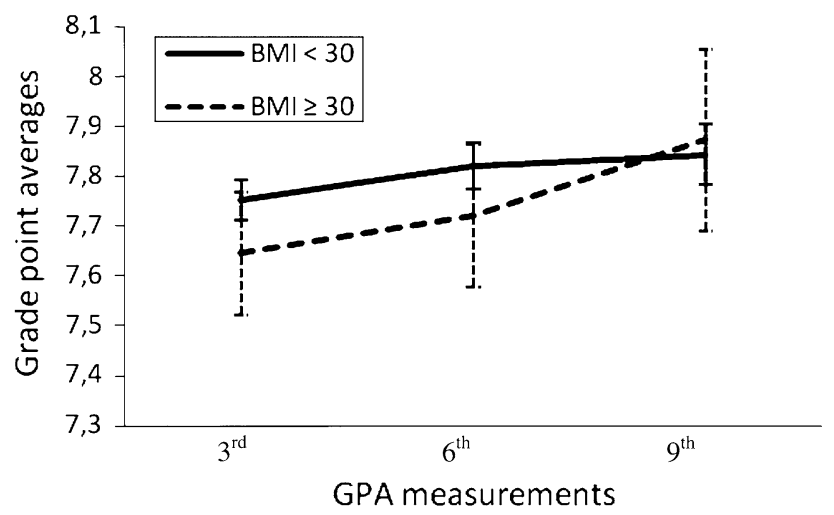

Fig. 2 Fully adjusted GPAs over the three measurements (3rd, 6th, and 9 th grade) among non-obese $(\mathrm{BMI}<30)$ and obese $(\mathrm{BMI} \geq 30)$ men

grade). Among men, there were no significant GPA differences between the obesity groups at any age ( $p$-values varying between 0.412 and 0.879 ).

\section{Discussion}

We found that school performance in early and middle adolescence predicted adulthood BMI and WC among women. The associations remained significant after controlling for birth weight, childhood BMI, physical activity, maternal and paternal BMI, and maternal education. The difference between the lowest and highest possible GPA was $0.62,0.80$, and $0.88 \mathrm{BMI}$ units, and $0.52,0.89$, and $0.92 \mathrm{~cm}$ in $\mathrm{WC}$, for age 9,12 , and 15 , respectively, indicating an increase of the effect with transition from elementary to junior high school. The results were similar when comparing obese $(\mathrm{BMI} \geq 30)$ to non-obese (BMI $<30$ ) individuals. In addition to the associations with single GPA measurements, low GPAs throughout the three measurements (aged 9, 12, and 15) were significantly associated with higher mean levels in BMI and WC among women.

Previously, obesity has been shown to be a predictor of later school performance $[15,17,18]$. Here we showed an opposite causality: low school performance may predict obesity even until adulthood.

We found that poor school performance was a risk factor of adult obesity only among women. This is consistent with some previous studies $[18,19,38]$ but not all $[15,22,25$, $26,30,31]$. Women are known to be more conscious about their school work [39]. Therefore, it is possible that females may experience poor school performance more stressful than males [40]. It is also possible that females are expected to perform better at school than males [41, 42]. Thus, poor school performance may cause higher stress among females than among males. Stress, in turn, is known to be related with overeating [43].

Poor school performance is a part of a problem tangle, indicating worsened social outcomes such as lower performance in subsequent education, poor work performance [44], lower grade of employment [45], and detrimental health behavior [46]. According to this, poor school performance may be a first indicator of an extensive health behavior risk clustering that may be a cause of adulthood obesity.

Several variables, i.e. birth weight, childhood BMI, maternal and paternal BMI, physical activity, and maternal education are known to confound the associations between school performance and obesity $[12,17,18,25,26]$. We controlled for these variables and found that the associations between school performance and obesity remained.

We found that grade point averages at different school stages predicted obesity in adulthood independently of the used obesity measurement. The BMI is a widely used measure for assessing general obesity whereas WC reflects the quantity of abdominal fat [1], and they both contribute independently to the CVD risk.

Although the effect sizes of the GPAs in explaining BMI and WC in adulthood were rather small, they explained similar amount of the variance as health risk behavior and psychological variables in predicting CVD risk and mortality [47]. Previous research has shown that poor school performance not only predicts social exclusion [45] but also predicts health-related risk behavior such as smoking [48] and excessive alcohol consumption [49, 50].

One limitation of the study is that self-reported grade point averages may be biased through recall problems. It has been suggested, however, that self-reported grades 
generally predict student outcomes to a similar extent as actual performance [44]. A further limitation is that of the original sample of 1,229 only 732 participants were included in this study. This might be a source of bias that has led to restriction in variance, possibly resulting in limited power of a statistical test to find associations. The persons lost to follow-up were more likely to be men, had lower school performance, higher childhood BMI, and were physically less active than the included participants. This may have led to distortion of the associations between school performance and obesity, i.e., the real association might be higher.

The effect of school performance on social risk factors is largely known but not much is known of its impact on health risk factors. We found that poor school performance at different school stages predicted obesity even after controlling for several variables that are known to be related with obesity. Our findings highly suggests that preventing children from drifting into poor school trajectories may be helpful in reducing obesity, which is one of the biggest health concerns among different generations in Western countries. Further research is needed to better understand the observed gender-related difference between poor school performance and adulthood obesity.

Acknowledgments This study was supported by the Academy of Finland (grants 124399 for L.K.-J., and 123621 for L.P.-R.), The Research Funds of the University of Helsinki (L.P.-R.), Alfred Kordelin's Foundation (S.A.), Oskar Öflund's Foundation (S.A.), Signe and Ane Gyllenberg's Foundation (L.K.-J., and M.H.), and Yrjö Jahnsson's Foundation (M.H.).

\section{References}

1. Branca F, Nikogosian H, Lobstein T. (Eds.) The challenge of obesity in the WHO European Region and the strategies for response. Geneva: Switzerland, World Health Organisation (WHO), 2007, 339 pp. Retrieved in July 10, 2008, from World Health Organisation Reports Online. Available from: www. euro.who.int/document/E90711.pdf.

2. Caballero B. The global epidemic of obesity: an overview. Epidemiol Rev. 2007;29(1):1-5.

3. Berghöfer A, Pischon T, Reinhold T, Apovian CM, Sharma AM, Willich SN. Obesity prevalence from a European perspective: a systematic review. BMC Publ Health. 2008;8(200):1-10.

4. Helakorpi S, Prättälä R, Uutela A. Suomalaisen aikuisväestön terveyskäyttäytyminen ja terveys, kevät 2007 [Health behaviour and health among Finnish adult population, spring 2007]. Publications of the National Public Health Institute, Finland, 6/2008, 208 pp. Available from: http://www.ktl.fi/attachments/suomi/ julkaisut/julkaisusarja_b/2008/2008b06.pdf.

5. Must A, Spadano J, Coakley EH, Field AE, Colditz G, Dietz WH. The disease burden associated with overweight and obesity. JAMA. 1999;282(16):1523-9.

6. Alexander JK. Obesity and coronary heart disease. Am J Med Sci. 2001;321(4):215-24.

7. Field AE, Coakley EH, Must A, Spadano JL, Laird N, Dietz WH, et al. Impact of overweight on the risk of developing common chronic diseases during a 10-year period. Arch Intern Med. 2001;161(13):1581-6.

8. McMillan DC, Sattar N, McArdle CS. ABC of obesity. Obesity and cancer. BMJ. 2006;333(7578):1109-11.

9. Pulkki-Råback L, Elovainio $\mathrm{M}$, Kivimäki $\mathrm{M}$, Raitakari OT, Keltikangas-Järvinen L. Temperament in childhood predicts body mass in adulthood: the cardiovascular risk in young finns study. Health Psych. 2005;24(3):307-15.

10. Roth J, Qiang X, Marbán SL, Redelt H, Lowell BC. The obesity pandemic: where have we been and where are we going? Obes Res. 2004;12(Suppl 2):S88-101.

11. Müller-Riemenschneider F, Reinhold T, Berghöfer A, Willich SN. Health-economic burden of obesity in Europe. Eur J Epidemiol. 2008;23(8):499-509.

12. Parsons TJ, Powers C, Logan S, Summerbell CD. Childhood predictors of adult obesity: a systematic review. Int J Obes Relat Metab Disord. 1999;23(Suppl 8):S1-107.

13. Heyneman SP. Student background and student achievement: what is the right question? Am J Educ. 2005;112(1):1-9.

14. Taras H, Potts-Datema W. Obesity and student performance at school. J Sch Health. 2005;75(8):291-5.

15. Mo-suwan L, Lebel L, Puetpaiboon A, Junjana C. School performance and weight status of children and young adolescents in a transitional society in Thailand. Int J Obes Relat Metab Disord. 1999;23(3):272-7.

16. Crosnoe R, Muller C. Body mass index, academic achievement, and school context: examining the educational experiences of adolescents at risk of obesity. J Health Soc Behav. 2004; 45(5):393-407.

17. Datar A, Sturm R, Magnabosco JL. Childhood overweight and academic performance: national study of kindergartners and firstgraders. Obes Res. 2004;12(1):58-68.

18. Datar A, Sturm R. Childhood overweight and elementary school outcomes. Int J Obes. 2006;30(9):1449-60.

19. Laitinen J, Power C, Ek E, Sovio U, Jarvelin MR. Unemployment and obesity among young adults in a northern Finland 1966 birth cohort. Int J Obes Relat Metab Disord. 2002;26(10):1329-38.

20. Shore SM, Sachs ML, Lidicker JR, Brett SN, Wright AR, Libonati JR. Decreased scholastic achievement in overweight middle school students. Obesity. 2008;16(7):1535-8.

21. Sigfusdottir ID, Kristjansson AL, Allegrante JP. Health behaviour and academic achievement in Icelandic school children. Health Educ Res. 2007;22(1):70-80.

22. Mikkilä V, Lahti-Koski M, Pietinen P, Virtanen SM, Rimpelä M. Associates of obesity and weight dissatisfaction among Finnish adolescents. Public Health Nutr. 2003;6(1):49-56.

23. Bin X, Chih-Ping C, Spruijt-Metz D, Reynolds K, Clark F, Palmer $\mathrm{PH}$, et al. Weight perception, academic performance, and psychological factors in Chinese adolescents. Am J Health Behav. 2006;30(2):115-24.

24. Huang TT, Goran MI, Spruijt-Metz D. Associations of adiposity with measured and self-reported academic performance in early adolescence. Obesity. 2006;14(10):1839-45.

25. Cottrell LA, Northrup K, Wittberg R. The extended relationship between child cardiovascular risks and academic performance measures. Obesity. 2007;15(12):3170-7.

26. Judge S, Jahns L. Association of overweight with academic performance and social and behavioral problems: an update from the early childhood longitudinal study. J Sch Health. 2007; 77(10):672-8.

27. Li X. A study of intelligence and personality in children with simple obesity. Int J Obes Relat Metab Disord. 1995;19(5):355-7.

28. Lahti-Koski M, Vartiainen E, Männistö S, Pietinen P. Age, education and occupation as determinants of trends in body mass index in Finland from 1982 to 1997. Int J Obes. 2000; 24(12):1669-76. 
29. Halkjaer J, Holst C, Sørensen TI. Intelligence test score and educational level in relation to BMI changes and obesity. Obes Res. 2003;11(10):1238-45.

30. Falkner NH, Neumark-Sztainer D, Story M, Jeffery RW, Beuhring T, Resnick MD. Social, educational, and psychological correlates of weight status in adolescents. Obes Res. 2001;9(1): 32-42.

31. Schwimmer JB, Burwinkle TM, Varni JW. Health-related quality of life of severely obese children and adolescents. JAMA. 2003;289(14):1813-9.

32. Swallen KC, Reither EN, Haas SA, Meier AM. Overweight, obesity, and health-related quality of life among adolescents: the National Longitudinal Study of Adolescent. Health Pediatr. 2005; 115(2):340-7.

33. Tershakovec AM, Weller SC, Gallagher PR. Obesity, school performance and behaviour of black, urban elementary school children. Int J Obes Relat Metab Disord. 1994;18(5):323-7.

34. Warschburger $P$. The unhappy obese child. Int $J$ Obes. 2005;29(Suppl 2):S127-9.

35. Åkerblom HK, Uhari M, Pesonen E, Dahl M, Kaprio EA, Nuutinen EM, et al. Cardiovascular risk in young Finns. Ann Med. 1991;23(1):35-9.

36. National Institute of Health and Clinical Excellence (NHS) (2006) Obesity: the prevention, identification, assessment, and management of overweight and obesity in adults and children. Clinical Guideline 43. National Institute of Health and Clinical Excellence (NHS). London: UK. Retrieved July 10, 2008, from National Institute of Health and Clinical Excellence Online. Available from: http://www.nice.org.uk/nicemedia/pdf/CG43 NICEGuideline.pdf.

37. Telama R, Yang X, Viikari J, Välimäki I, Wanne O, Raitakari O. Physical activity from childhood to adulthood: a 21-year tracking study. Am J Prev Med. 2005;28(3):267-73.

38. Morrill CM, Leach JN, Shreeve WC, Radebaugh MR. Teenage obesity: an academic issue. Int J Adolesc Youth. 1991;2(4):24550 .

39. Steinmayr R, Spinath B, Neubauer AC. Sex differences in school achievement: what are the roles of personality and achievement motivation? Eur J Person. 2008;22(3):185-209.
40. West P, Sweeting H. Fifteen, female and stressed: changing patterns of psychological distress over time. J Child Psychol Psychiatry Discipl. 2003;44(3):399-411.

41. Entwisle DR, Hayduk LA. Academic expectations and the school attainment of young children. Soc Educ. 1981;54(1):34-50.

42. Entwisle DR, Baker DP. Gender and young children's expectations for performance in arithmetic. Dev Psychol. 1983;19(2) :200-9.

43. Torres SJ, Nowson CA. Relationship between stress, eating behavior, and obesity. Nutrition. 2007;23(11):887-94.

44. Kuncel NR, Credé M, Thomas LL. The validity of self-reported grade point averages, class ranks, and test scores: a meta-analysis and review of the literature. Rev Educ Res. 2005;75(1):63-82.

45. Kokko K, Bergman LR, Pulkkinen L. Child personality characteristics and selection into long-term unemployment in Finnish and Swedish longitudinal samples. Int J Behav Dev. 2003;27(2): 134-44.

46. Lynch JW, Kaplan GA, Salonen JT. Why do poor people behave poorly? Variation in adult health behaviours and psychosocial characteristics by stages of the socioeconomic lifecourse. Soc Sci Med. 1997;44(6):809-19.

47. Loh C, Rutledge T. Effect sizes and statistical testing in the determination of clinical significance in behavioral medicine research. Ann Behav Med. 2004;27(2):138-45.

48. Bryant AL, Schulenberg J, Bachman JG, O'Malley PM, Johnston LD. Understanding the links among school misbehavior, academic achievement, and cigarette use: a national panel study of adolescents. Prev Sci. 2000;1(2):71-87.

49. Huurre T, Lintonen T, Kaprio J, Pelkonen M, Marttunen M, Aro $\mathrm{H}$. Adolescent risk factors for excessive alcohol use at age 32 years A 16-year prospective follow-up study. Soc Psychiatry Psychiatr Epidemiol. 2010;45(1):125-34.

50. Pitkänen T, Kokko K, Lyyra A, Pulkkinen L. A developmental approach to alcohol drinking behaviour in adulthood: a follow-up study from age 8 to age 42. Addiction. 2008;103(Suppl 1):48-68. 